\title{
SARS-CoV-2 analysis on environmental surfaces collected in an intensive care unit. Keeping Ernest Shackleton's spirit.
}

\section{Dolores Escudero}

Hospital Universitario Central de Asturias

Jose Antonio Boga ( $\nabla$ joseantonio.boga@sespa.es )

Hospital Universitario Central de Asturias https://orcid.org/0000-0002-5500-9972

Javier Fernández

Hospital Universitario Central de Asturias

Lorena Forcelledo

Hospital Universitario Central de Asturias

Salvador Balboa

Hospital Universitario Central de Asturias

Rodrigo Albillos

Hospital Universitario Central de Asturias

Iván Astola

Hospital Universitario Central de Asturias

\section{Emilio García-Prieto}

Hospital Universitario Central de Asturias

Marta Elena Álvarez-Argüelles

Hospital Universitario Central de Asturias

Gabriel Martín

Hospital Universitario Central de Asturias

Josu Jiménez

Hospital Universitario Central de Asturias

Fernando Vázquez

Hospital Universitario Central de Asturias

\section{Research}

Keywords: SARS-CoV-2, COVID-19, ICU, ICU environmental contamination

Posted Date: September 28th, 2020

DOl: https://doi.org/10.21203/rs.3.rs-52899/v2 
License: (c) (i) This work is licensed under a Creative Commons Attribution 4.0 International License. Read Full License

Version of Record: A version of this preprint was published on November 23rd, 2020. See the published version at https://doi.org/10.1186/s40635-020-00349-5. 


\section{Abstract}

Background: Intensive care unit workers are at high risk of acquiring COVID-19 infection, especially when performing invasive techniques and certain procedures that generate aerosols $(<5 \mu \mathrm{m})$. Therefore, one of the objectives of the health systems should implement safety practices to minimize the risk of contagion among these health professionals. Monitoring environmental contamination of SARS-CoV-2 may help to determine the potential of the environment as a transmission medium in an area highly exposed to SARSCoV-2, such as an intensive care unit. The objective of the study was to analyze the environmental contamination by SARS-CoV-2 on surfaces collected in an intensive care unit, which is dedicated exclusively to the care of patients with COVID-19 and equipped with negative pressure of -10 pascals and an air change rate of 20 cycles per hour. Furthermore, all ICU workers were tested for COVID-19 by quantitative RT-PCR and ELISA methods.

Results: A total of 102 samples (72 collected with pre-moistened swabs used for collection of nasopharyngeal exudates and 30 with moistened wipes used in the environmental microbiological control of the food industry) were obtained from ventilators, monitors, perfusion pumps, bed rails, lab benches, containers of personal protective equipment, computer keyboards and mice, telephones, workers' shoes, floor and other areas of close contact with COVID-19 patients and healthcare professionals who cared for them. The analysis by quantitative RT-PCR showed no detection of SARSCoV-2 genome in environmental samples collected by any of the two methods described. Furthermore, none of the ICU workers was infected by the virus.

Conclusions: Presence of SARS-CoV-2 on the ICU surfaces could not be determined supporting that a strict cleaning protocol with sodium hypochlorite, a high air change rate and a negative pressure in the ICU are effective in preventing environmental contamination. These facts together with the protection measures used could also explain the absence of contagion among staff inside ICUs.

\section{Background}

In December 2019, a new betacoronavirus causing pneumonia and acute respiratory distress syndrome was detected in China. The virus and the disease were called SARS-CoV-2 and Coronavirus Disease (COVID)-19, respectively ${ }^{1-3}$. In a few months, it spread rapidly throughout the world being officially declared as a pandemic by the World Health Organization (WHO) on March 11, $2020^{4}$.

The main modes of transmission of the virus is through respiratory droplets $(>5 \mu \mathrm{m})$, aerosols $(<5 \mu \mathrm{m})$ and fomites contaminated with respiratory secretions ${ }^{5,6}$. Intensive Care Unit (ICU) workers are at high risk when performing invasive techniques and certain procedures that generate aerosols while working in an environment highly exposed to SARS-CoV-2. Therefore, one of the objectives of the health systems should implement safety practices to minimize the risk of contagion among health professionals.

The aim of this study is to analyze the environmental contamination by SARS-CoV-2 on surfaces of an ICU dedicated to treating patients with COVID-19. 


\section{Methods}

From February 29th to June 5th, a total of 86 patients with COVID-19 were admitted in our hospital (62 in a multipurpose ICU and 24 in a cardiac ICU managed by specialists in intensive medicine). The multipurpose ICU had 44 beds distributed in 5 Units ( 4 units with 10 beds and 1 unit with 4 beds, all boxes are independent with a surface of $22 \mathrm{~m}^{2}$ ). During the studied period, the acute phase of the pandemic, all ICU beds were exclusively used to treat patients diagnosed with COVID-19. All the patients had a high level of severity; most of them required mechanical ventilation and some presented failure of other organs such as kidney failure with hemofiltration. The space within the ICU was divided into three areas of risk exposure (high, medium and low). Inside the boxes (high risk area), the professionals worked with personal protective equipment (PPE). A security perimeter, two meters from the entrance of the isolation rooms, was marked on the ground with a red stripe (medium risk area). In this area, professionals had to use a surgical mask. The central area of the unit, which is a space intended for administrative work with electronic medical records, was considered as a low risk area and work without a mask was allowed. All the ICU units were equipped with negative pressure of -10 pascals $(\mathrm{Pa})$ and an air flow circuit with circulation from the central area to the boxes with an air change rate of 20 cycles per hour (Figures 1 and 2). The mean temperature was $22^{\circ} \mathrm{C}$ (range $22^{\circ} \mathrm{C}-24^{\circ} \mathrm{C}$ ) and the humidity was $50 \%$ (range $45 \%-55 \%$ ). The ICU was cleaned with detergent and $0.05 \%$ sodium hypochlorite in the morning and afternoon shift. Some surfaces such as the pagers or the EPI face masks were disinfected with $70 \%$ ethanol following the recommendations of the $\mathrm{ECDC}^{7}$.

From 16 to 27 April, one hundred and two environmental samples were collected in the three risk areas at different times in the morning and afternoon using two methods: 1) The first 72 samples were collected by pre-moistened sterile swabs (Copan Liquid Amies Elution Swab, Copan Diagnostics, Murrieta, CA), which are used to collect nasopharyngeal exudates and 2) the next 30 samples were collected by moistened wipes 23x23 cm (WIPES CHI 100N, Biomerieux, Marcy-l'Etoile, France), which are commonly used in the collection of environmental samples for microbiological control in the food industry, detecting pathogens such as Listeria monocytogenes or Salmonella spp. A larger surface can be covered with this method. All samples were immediately sent to the laboratory and processed to SARS-CoV-2 detection.

The presence of SARS-CoV-2 was analyzed by detecting viral genome using a multiple quantitative retrotranscriptase (RT)-PCR. Nucleic acids were purified by MagNa Pure 96 System (Roche, Geneva, Switzerland) from the swabs transport medium or from the eluates obtained after incubating the wipes in MEM medium (Dominique Dutscher, Brumath, France) at $37^{\circ} \mathrm{C}$ for half an hour. The extracts were subjected to an amplification reaction using TaqMan Fast 1-Step Master Mix (Life technologies, Carlsbad, CA) supplemented with a mixture of primers (Thermo Fisher Scientific, Walthman, MA) and taqman MGB probes (Applied Biosystems, Foster City, CA) directed against ORF1 ab and N genes (Table 1). Amplifications and subsequent analysis were carried out using the Applied Biosystems 7500 Real-time PCR System.

\section{Results}


A total of 72 environmental samples including floor, ventilators, perfusion pumps, monitors, bed rails, containers, computer keyboards and mouses or workers' shoe soles were initially collected using premoistened sterile swabs in the three risk areas (Table 2). No SARS-CoV-2 genome was detected in any of the samples. To discard that the area of collection was small, a larger surface was analyzed by using moistened wipes. Thus, a new batch of 30 samples, whose type and number are shown in Table 3 , was collected in the same risk areas using moistened wipes. Although covered surface was significantly larger, no genome of SARS-CoV-2 was detected.

\section{Discussion}

A report published in April 2020 by the European Center for Disease Control and Prevention (ECDC) highlights that the percentage of healthcare professionals infected by SARS-CoV-2 in Spain is the highest in the world with $20 \%$ of all reported cases, followed by Italy (10\%), China $(3.8 \%)$ and the USA $(3 \%)^{8}$. According to data from the Spanish Ministry of Health, 52,643 health workers had been infected on July 9, representing more than $22 \%$ of all infections ${ }^{9}$. At the end of April, 237 workers from the ICU of our hospital were tested for detection of SARS-CoV-2 genome and antibodies by PCR and ELISA technique, respectively. All of them were negative suggesting a low circulation of the virus among these professionals.

Some experimental studies have reported that SARS-CoV-2 can remain viable in the air generated by aerosols for up to 3 hours, and on surfaces of copper, cardboard, stainless steel and plastic for 4, 24, 48 and 72 hours respectively ${ }^{10}$. Previous studies have also found other coronaviruses, such as SARS and MERS, in air samples within aerosols suggesting a possible air transmission ${ }^{11}$. Guo et al ${ }^{12}$ analyzed environmental contamination in surfaces collected in several yards of a hospital in Wuhan, including an ICU with an air change rate of 16 cycles per hour (no equipment with negative pressure is reported). They found that the most contaminated surfaces were those that had frequent contact with the hands of workers and patients, such as computer mice, trash cans, sickbed handrails and door knobs. Furthermore, Guo et al ${ }^{12}$ found that virus was detected in $70 \%$ of the ICU floor samples and half of the medical staff's shoe soles, suggesting a possible function of the shoes as carriers of the virus. Santarpia et al $^{13}$ analyzed surface and aerosol samples collected in an isolation unit for asymptomatic or mildly ill patients and in a hospitalization area of the University of Nebraska Medical Center by RT-PCR for SARSCoV2. Although the method of collection is not explained in the study, the virus was detected in a high percentage of personal objects such as mobile phones, television remote controls, personal computers or patient lenses, as well as on environmental surfaces such as bed rails, floor, vents and medical equipment of patients with COVID-19 (pulse oximetry, nasal cannula and incentive spirometer). Razzini K et $\mathrm{al}^{14}$ found SARS-CoV-2 RNA in 37 environmental samples. Viral RNA was detected in $35 \%$ and $50 \%$ of the samples obtained in the ICU and in areas considered semi-contaminated (undressing room), respectively. No viral RNA was detected in clean areas. Other authors also found environmental contamination in the air and surfaces of different hospital areas ${ }^{15-17}$ in very different proportions $(5 \%$ $52 \%$ of the samples). Although Zhou et al found viral RNA in $52 \%$ of the environmental samples in a 
London hospital; they could not grow the virus in Vero E6 and Caco 2 cells. This fact support that genome detection does not imply the viability and infective capacity of the virus ${ }^{17}$. These authors also reported a surprisingly low environmental contamination in the ICU in relation to other hospital areas ${ }^{17}$. Other studies also reported environmental contamination in towel bowl of the bathrooms suggesting that fecal shedding could be a potential route of transmission ${ }^{18}$. Although these studies showed a significant environmental contamination in areas with COVID19 patients based on detection of RNA from SARS-CoV2 , no infection among health workers was reported, which is explained by the implementation of effective protection measures ${ }^{13}$.

In contrast to these studies, Colaneri et al ${ }^{19}$ did not detect SARS-CoV-2 genome in environmental samples collected using moistened swabs in a hospital in Northern Italy. Such as the authors state, the low number of samples is a limitation of this study. Nevertheless, our results obtained by analyzing a higher number of samples (102 vs 16) support the no detection of SARS-CoV-2 RNA in environmental samples from hospital areas where patients with COVID-19 are attended. A possible limitation of our study is that the protocol cleaning, which was performed twice per day (morning and afternoon), influenced in the results. To avoid this limitation and given that SARS-CoV-2 can remain viable on surfaces between 4-72 hours ${ }^{10}$, samples were collected at different morning/afternoon hours along 15 days. Thus, the time from cleaning to sampling was variable. In any case, a possible explanation of the lack of environmental contamination could be a strict cleaning protocol with sodium hypochlorite, a high air change rate and a negative pressure in the ICU. These facts together with the protection measures used could also explain the absence of contagion among healthcare professionals in our ICU.

\section{Conclusions}

To our knowledge, this is the first study on environmental contamination by SARS-CoV-2 in a Spanish ICU. Our results indicate the lack of SARS-CoV-2 on the ICU surfaces supporting that personal protection, decontamination procedures and negative pressure settings are effective in preventing environmental contamination and protecting the staff and patients inside intensive care units. The COVID-19 pandemic is a huge challenge to our health systems. The safety of professionals must be a priority to prevent the collapse of health systems and avoid transmission from hospitals to the rest of the community. The study of the transmission routes, including the role of contaminated environmental samples, is a key element to establish public health policies. Strategies to monitor surfaces and lowering the environmental viral load are necessary to minimize the risk of transmission and to maintain Ernest Shackleton's spirit, the protection of the crew, the health professionals.

\section{Declarations}

\section{Acknowledgments}

To all ICU professionals for their effort and tireless work in caring for patients with COVID-19. To Dr. Sergio Pérez-Holanda for his invaluable support in this and other collaborations. 


\section{Ethics approval and consent to participate}

Not applicable. Our manuscript does not involve any animals, humans, human data, human tissue or plants, please state "in this section.

\section{Consent for publication}

Not applicable. Our manuscript does not contain any individual persons data.

\section{Availability of data and materials}

All datasets on which the conclusions of this manuscript rely are presented in the main paper

\section{Competing interests}

None of the authors has financial and non-financial competing interests.

\section{Funding}

This investigation has not received funding from any public, private or non-profit agent.

\section{Authors' contributions}

D Escudero designed the study and wrote the manuscript. JA Boga, J Fernández, L Forcelledo, E GarcíaPrieto, ME Álvarez-Argüelles, J Jiménez and F Vázquez participated in the preparation and correction of the manuscript. S Balboa, R Albillos, G Martín and D Escudero collected the samples.

\section{References}

1. Huang C, Wang Y, Li X, Ren L, Zhao J, Hu Y, et al (2020) Clinical features of patients infected with 2019 novel coronavirus in Wuhan, China. Lancet 395: 497-506.

2. Zhu N, Zhang D, Wang W, Li X, Yang B, Song J, et al (2020) A novel coronavirus from patients with pneumonia in China, 2019. N Engl J Med 382: 727-733.

3. Wang D, Hu B, Hu C, Zhu F, Liu X, Zhang J, et al (2020) Clinical characteristics of 138 hospitalized patients with 2019 novel coronavirus-infected pneumonia in Wuhan, China. JAMA 323:1061-1069

4. WHO Director-General's opening remarks at the media briefing on COVID-19 (2020) Available in: https://www.who.int/dg/speeches/detail/who-director-general-s-opening-remarks-at-the-mediabriefing-on-covid-19-20-march-2020.

5. Li Q, Guan X, Wu P, Wang X, Zhou L, Tong Y, et al (2020) Early transmission dynamics in Wuhan, China, of novel coronavirus-infected pneumonia. N Engl J Med 382:1199-1207.

6. Peng X, Xu X, Li Y, Cheng L, Zhou X, Ren B (2020) Transmission routes of 2019-nCoV and controls in dental practice. Int J Oral Sci. 12: 9. 
7. European Centre for disease prevention and control (ECDC) (2020) Disinfection of environments in healthcare and nonhealthcare settings potentially contaminated with SARS-CoV-2. Available in: https://www.ecdc.europa.eu/sites/default/ files/documents/Environmental-persistence-ofSARS_CoV_2-virus-Options-for-cleaning2020-03-26_0.pdf

8. European Centre for disease prevention and control (ECDC) (2020) Coronavirus disease 2019 (COVID-19) in the EU/EEA and the UK-ninth update. Available in: https://www.ecdc.europa.eu/sites/default/files/documents/covid-19-rapid-risk-assessmentcoronavirus-disease-2019-ninth-update-23-april-2020.pdf.

9. Spanish Ministry of Health. (2020) Actualización nº 160. Enfermedad por el coronavirus (COVID-19). Available in: https://www.mscbs.gob.es/profesionales/ saludPublica/ccayes/alertasActual/nCovChina/documentos/Actualizacion_160__COVID-19.pdf

10. Doremalen N Van, Bushmaker T, Morris DH, Holbrook MG, Gamble A, Williamson BN et al (2020) Aerosol and Surface Stability of SARS-CoV-2 as Compared with SARS-CoV-1. N Engl J Med 382:1564-1567.

11. Booth TF, Kournikakis B, Bastien N, Ho J, Kobasa D, Stadnyk L, et al (2005) Detection of airborne severe acute respiratory syndrome (SARS) coronavirus and environmental contamination in SARS outbreak units. J Infect Dis. 191:1472-1477.

12. Guo ZD, Wang ZY, Zang SF, Li X, Li L, Li C, et al. (2020) Aerosol and Surface Distribution of severe acute respiratory syndrome coronavirus 2 in hospital wards, Wuhan, China, 2020. Emerg Infect Dis 2:1586-1591.

13. Santarpia JI, Rivera DN, Herrera V, Morwitzer MJ, Creager H, Santarpia GW, et al (2020) Transmission potential of SARS-CoV-2 in viral shedding observed at the University of Nebraska Medical Center. 03.23.20039446.

14. Razzini K, Castrica M, Menchetti L, Maggi L, Negroni L, Orfeo NV, et al. (2020) SARS-CoV-2 RNA detection in the air and on surfaces in the COVID-19 ward of a hospital in Milan, Italy. Science Total Environ 742:

15. Mouchtouri VA, Koureas M, Kyritsi M, Vontas A, Kourentis L, Sapounas S, et al. (2020) Environmental contamination of SARS-CoV-2 on surfaces, air-conditioner and ventilation systems. Int $\mathrm{J}$ Hyg Environ Health. 0230:113599.

16. Peyrony O, Ellouze S, Fontaine JP, Thegat-Le Cam M, Salmona M, Feghoul L, et al. (2020) Surfaces and equipment contamination by severe acute respiratory syndrome coronavirus 2 (SARS-CoV-2) in the emergency department at a university hospital. Int J Hyg Environ Health. 230:113600.

17. Zhou, J, Otter J, Price JR, Cimpeanu C, Garcia DM, Kinross J. et al (2020) Investigating SARS-CoV-2 surface and air contamination in an acute healthcare setting during the peak of the COVID-19 pandemic in London. Clin Infect Dis ciaa905.

18. Ong SWX, Tan YK, Chia PY, et al (2020) Air, surface environmental, and personal protective equipment contamination by severe acute respiratory syndrome coronavirus 2 (SARS-CoV-2) from a symptomatic patient. JAMA 323:1610-1612. 
19. Colaneri M, Seminari E, Piralla A, et al (2020) Lack of SARS-CoV-2 RNA environmental contamination in a tertiary referral hospital for infectious diseases in Northern Italy J Hosp Infect 105:474-476.

20. US Centers for Disease Control and Prevention (2020) 2019-Novel coronavirus (2019-nCoV) real-time rRT-PCR panel primers and probes. Available in: https://www.cdc.gov/coronavirus/2019-ncov/lab/rtpcr-panel-primer-probes.html

\section{Tables}

Table 1. Primers and probes used to detect SARS-CoV-2.

\begin{tabular}{|c|c|c|c|c|}
\hline Design & Position & Name & Sequence $\left(5^{\prime}-3^{\prime}\right)$ & Gen \\
\hline \multirow{3}{*}{$\begin{array}{l}\text { In } \\
\text { house }\end{array}$} & Sense primer & CoV-2-OVI-S & ATCAAGTTAATGGTTACCCTAACATGT & \\
\hline & $\begin{array}{l}\text { Antisense } \\
\text { primer }\end{array}$ & CoV-2-OVI-A & AACCTAGCTGTAAAGGTAAATTGGTACC & ORF1ab \\
\hline & $\begin{array}{l}\text { Probe MGB } \\
\text { FAM }\end{array}$ & CoV-2-OVI-FAM & CCGCGAAGAAGCTA & \\
\hline \multirow[t]{3}{*}{$\mathrm{CDC}^{1}$} & Sense primer & 2019-nCoV_N1-F & GACCCCAAAATCAGCGAAAT & \\
\hline & $\begin{array}{l}\text { Antisense } \\
\text { primer }\end{array}$ & 2019-nCoV_N1-R & TCTGGTTACTGCCAGTTGAATCTG & Gen N \\
\hline & $\begin{array}{l}\text { Probe MGB } \\
\text { VIC }\end{array}$ & $\begin{array}{l}\text { 2019-nCoV_N1-P- } \\
\text { VIC }\end{array}$ & CCGCATTACGTTTGGT² & \\
\hline
\end{tabular}

${ }^{1}(20)$

${ }^{2}$ Probe sequence has been shortened as it is a MGB probe

Table 2. Environmental samples $(n=72)$ collected in the ICU by pre-moistened sterile swabs and PCR results. 


\begin{tabular}{|ll|}
\hline Sample (n) & PCR \\
\hline Door knob (2) & nd \\
\hline Chair (1) & nd \\
\hline Telephone (4) & nd \\
\hline Keyboard computer (8) & nd \\
\hline Mouse computer (3) & nd \\
\hline Sink faucet (4) & nd \\
\hline Perfusion pump (3) & nd \\
\hline Cart (3) & nd \\
\hline Door handle (1) & nd \\
\hline ICU workers shoe sole (13) & nd \\
\hline Table (3) & nd \\
\hline Bench (6) & nd \\
\hline Bed, bed rail, mattress (8) & nd \\
\hline Ventilator (6) & nd \\
\hline Bag valve mask (2) & nd \\
\hline Blood pressure cuff (2) & nd \\
\hline ECG electrodes (1) & nd \\
\hline Oxygen supply system (2) & nd \\
\hline
\end{tabular}

nd, no detectable signal or $\mathrm{Ct}>40$.

Table 3. Environmental samples $(n=30)$ collected in the ICU by moistened wipes and PCR results. 


\begin{tabular}{|ll|}
\hline Sample ( ) & PCR \\
\hline Door knob (1) & nd \\
\hline Chair (1) & nd \\
\hline Waste container (2) & nd \\
\hline Sink faucet (1) & nd \\
\hline Perfusion pump (3) & nd \\
\hline Tracheal tube (exterior) (1) & nd \\
\hline ICU workers' shoe sole (3) & nd \\
\hline Sling (1) & nd \\
\hline Bench (5) & nd \\
\hline Bed, bed rail (4) & nd \\
\hline Ventilator (3) & nd \\
\hline Ward floor (3) & nd \\
\hline Mouse/keyboard computer (2) & nd \\
\hline
\end{tabular}

nd, no detectable signal or $\mathrm{Ct}>40$.

Figures 


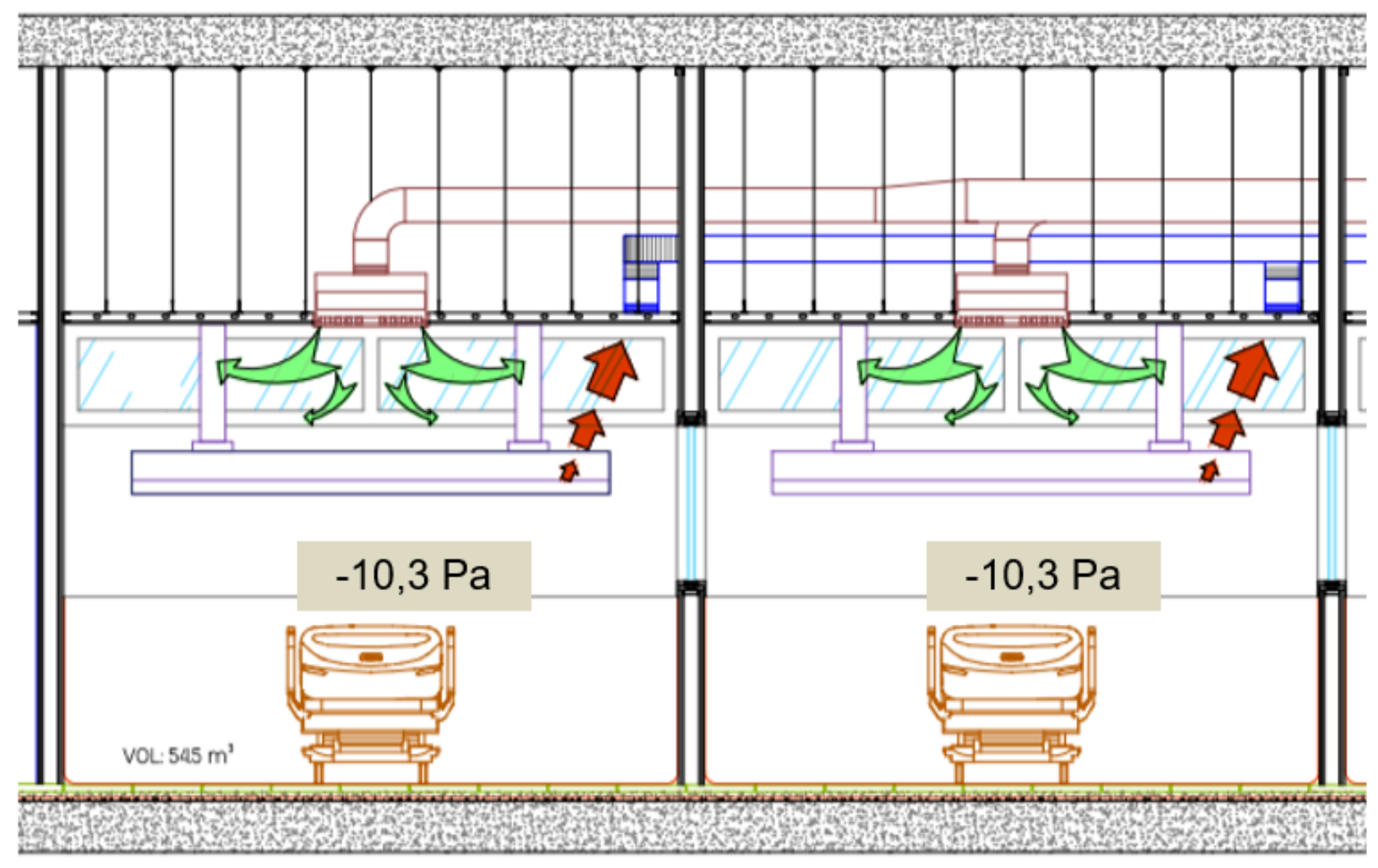

Figure 1

Representation of the directions of the air flow in ICU rooms. Fresh air (green arrows) and dirty air (red arrows). 


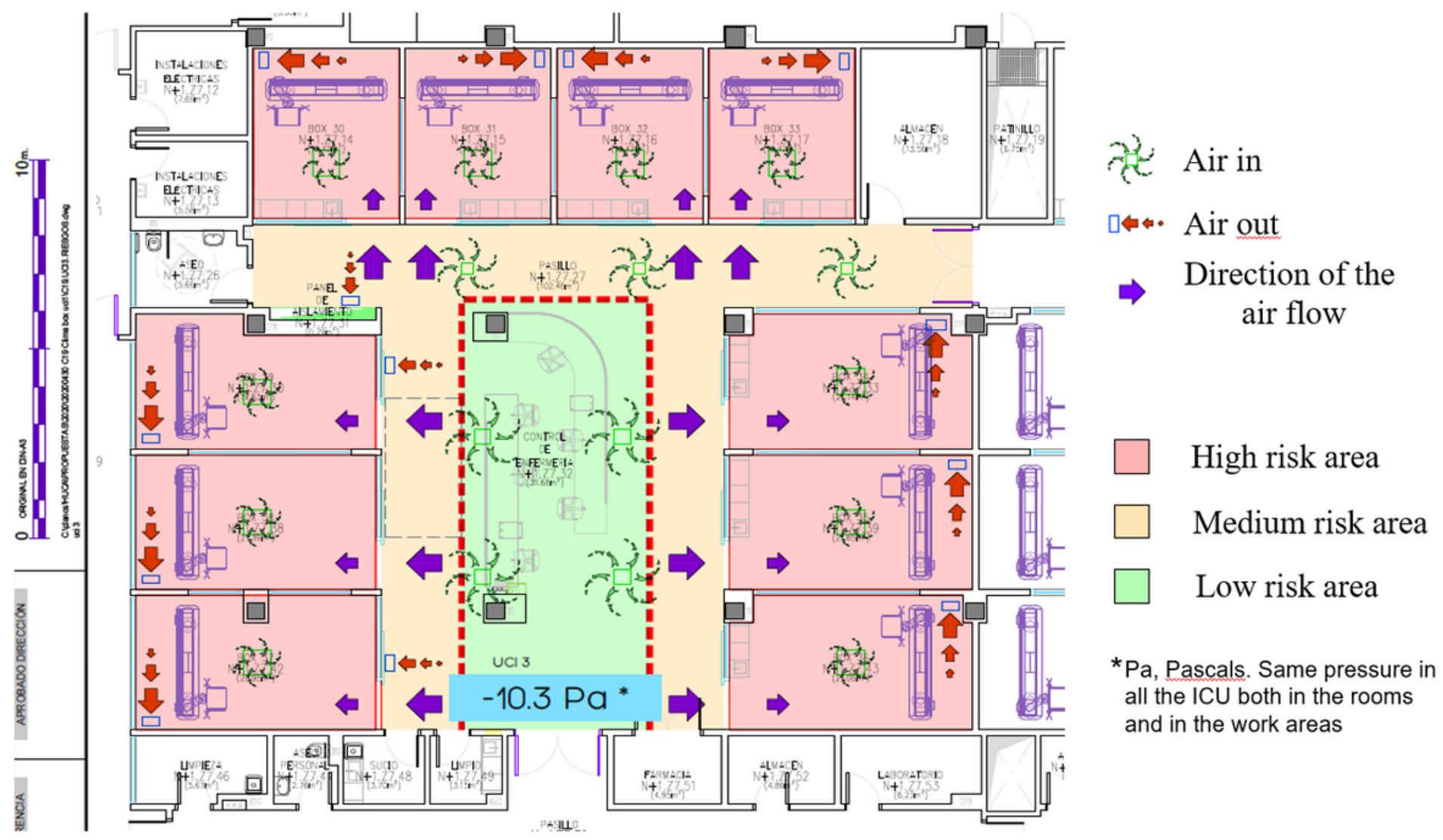

\section{Figure 2}

Map showing the high, medium, and low risk areas, as well as directions of the air flows of the intensive care unit. The value of the negative pressure is indicated. 